\title{
ENSACAMENTO DE FRUTOS DO TOMATEIRO VISANDO AO CONTROLE DE PRAGAS E À REDUÇÃO DE DEFENSIVOS
}

\author{
Alexandre Luis Jordão ${ }^{1,3 *}$; Octávio Nakano² \\ ${ }^{1}$ IEPA - Instituto de Pesquisas Científicas e Tecnológicas do Estado do Amapá, Rod. Juscelino Kubistchek, km 10 - \\ Fazendinha - CEP: 68912-250 - Macapá, AP. \\ ${ }_{3}^{2}$ Depto. de Entomologia, Fitopatologia e Zoologia Agrícola - USP/ESALQ, C.P. 9 - CEP: 13418-900 - Piracicaba, SP. \\ ${ }^{3}$ Bolsista FAPESP. \\ *Autor correspondente <aljordao@hotmail.com>
}

RESUMO: O ensacamento de frutos durante o seu desenvolvimento na planta, além do objetivo de controlar pragas pode reduzir resíduos de defensivos e manejar aspectos qualitativos. Com o objetivo de controle das pragas Neoleucinodes elegantalis, Helicoverpa zea e Tuta absoluta e redução de resíduos de inseticidas, pencas de tomates, foram ensacadas com papel-manteiga. Além do efeito do ensacamento, foram testados dois repelentes de insetos. Foram realizados cinco tratamentos. A eficiência do ensacamento e dos repelentes foi verificada por meio do número médio de lagartas encontradas por tratamento. A quantidade de resíduo de metamidofós encontrada nos frutos ensacados e nos frutos expostos diretamente à pulverização foi comparada ao limite máximo permitido. Verificou-se, também, a qualidade dos frutos produzidos pelo método do ensacamento através de análises físico-químicas dos tomates. Os custos do método do ensacamento foram comparados aos do método químico. O ensacamento, associado ou não aos repelentes, reduz o ataque das lagartas $N$. elegantalis e $H$. zea aos frutos. Para o controle de $T$. absoluta é necessária a integração com controle químico nas épocas de maior infestação. Os frutos não ensacados possuíam quantidade de metamidofós seis vezes superiores ao máximo tolerado e os frutos ensacados quantidade três vezes inferiores a este limite. O ensacamento das pencas de tomates não modificou os parâmetros físico-químicos dos frutos produzidos. O método do ensacamento requer maior investimento econômico, porém esse investimento atinge um mercado diferencial, com preços mais elevados.

Palavras-chave: Lycopersicon esculentum, Neoleucinodes elegantalis, Helicoverpa zea, Tuta absoluta, custo de produção

\section{PAPER BAGS FOR PEST CONTROL AND PESTICIDE USE REDUCTION ON TOMATO FRUITS}

\begin{abstract}
The development of fruits in paper bags aims at the control of pests, reduction of pesticide residues and the management of qualitative aspects. This work evaluates the efficacy of paper bags in combination with deodorant tablets and garlic clove on the control of the pest agents Neoleucinodes elegantalis, Helicoverpa zea and Tuta absoluta on bunches of tomatoes. Five treatments were set up: paper bags carrying deodorant tablets, paper bags with garlic cloves, paper bags containing no repellent, control without repellent and control with the insecticide methamidophos. The results were assessed by the number of caterpillars found on the fruits. Fruits protected in wax-paper bags and fruits exposed directly to methamidophos during application were compared in regard to the maximum tolerable residue. The use of paper bags reduced the number of caterpillars of $N$. elegantalis and $H$. zea per fruit. Pesticide residues on fruits without bags were six times higher than the maximum tolerable. Fruits within paper bags presented residue levels three times lower than the maximum. The use of paper bags for protection of tomato fruits did not alter fruit characteristics. Considering the costs, the use of paper bags for tomato cropping requires higher initial investment, but it supplies a differential market with higher prices.

Key words: Lycopersicon esculentum, Neoleucinodes elegantalis, Helicoverpa zea, Tuta absoluta, production cost
\end{abstract}

\section{INTRODUÇÃO}

Devido ao grande número de pragas que causam danos em hortaliças, o agricultor se vê obrigado a utilizar métodos de controle preventivos, aplicando uma série de defensivos.

No Brasil, as principais espécies de insetos danosos aos frutos do tomateiro estaqueado, de acordo com Nakano (1989), são: Neoleucinodes elegantalis (Guenée, 1854) (Lepidoptera: Crambidae: Pyraustinae) ou broca-pequena ou perfurador dos frutos do tomateiro, Helicoverpa zea (Boddie, 1850) (Lepidoptera: Noctuidae) ou broca-grande, Tuta absoluta (Meyrick, 1917) (Lepidoptera: Gelechiidae) ou traça-do-tomateiro e Phthorimaea operculella (Zeller, 1873) (Lepidoptera: Gelechiidae) ou traça-da-batatinha.

A utilização de repelentes de insetos como técnica de controle de pragas foi incentivada e avaliada por Schreck (1977) em que, segundo sua descrição, é um método que contribui muito para a proteção ambiental. 
Moreira (1995) e Moreira et al. (1996) revelaram que em Viçosa (MG), 90,3\% dos tomaticultores não observavam o período de carência dos agrotóxicos e que $62,4 \%$ não utilizavam nenhum equipamento de proteção individual durante sua aplicação. O inseticida mais freqüentemente utilizado era o metamidofós e muitos outros produtos utilizados para fins fitossanitários não eram recomendados para a cultura. Constataram, também, que o problema dos agrotóxicos referia-se ao modo como eram utilizados e que grande parte dos aplicadores estavam com quantidade de resíduos de metamidofós no sangue acima do limite máximo tolerado.

Apesar de haver pouca literatura científica sobre o assunto, sabe-se que o ensacamento como medida de proteção de frutos é utilizado com sucesso na cultura da macieira, pessegueiro, goiabeira e mangueira contra as moscas-das-frutas Anastrepha spp. (Diptera: Tephritidae) e Ceratitis capitata (Wied., 1824) (Diptera: Tephritidae). Ensacam-se, também, os frutos do maracujazeiro para protegê-los das moscas-das-frutas e do percevejo, Diactor bilineatus (Fabr., 1803) (Hemiptera-Heteroptera: Coreidae). Os saquinhos utilizados geralmente possuem características próprias de acordo com a cultura. Em nespereira, o cacho é revestido com saquinhos de papel permeável para impedir o ataque de aves e insetos (Ramos, 1994). Na bananicultura brasileira, utilizam-se sacos maiores, de polietileno, contra tripes. O mesmo método de controle também é utilizado na Espanha (Gowen, 1995; Jannoyer \& Chillet, 1997).

O ensacamento dos frutos, além do controle de pragas, pode ter outras funções. No Japão, por exemplo, ensacam-se maçãs com o objetivo de manejar a tonalidade da coloração dos frutos (Machuca Neto, 1988). Em uvas, os espanhóis fazem o ensacamento do cacho com finalidade fitossanitária e para manter a uniformidade de coloração, por este motivo, recebem um selo de qualidade como medida de distinção durante a comercialização (Rivadulla, 1996).

Com o objetivo de controle das pragas dos frutos $N$. elegantalis, $H$. zea, T. absoluta e a redução de resíduos de inseticidas em frutos do tomateiro, foram realizados ensaios de ensacamento de pencas de tomates, associado ao uso de repelentes. Verificaramse, também, as possíveis modificações na qualidade dos tomates e os custos do método adotado, em comparação ao método químico de controle.

\section{MATERIAL E MÉTODOS}

\section{Ensacamento de frutos do tomateiro visando ao controle de pragas}

No período de 25 de março de 1998 a 15 de abril de 1999, foram realizados três ensaios de ensacamento das pencas dos tomateiros, instalados em diferentes épocas e em dois locais distintos. O primeiro ensaio foi iniciado em 25 de março de 1998 e o segundo em 01 de setembro de 1998. Ambos foram instalados nas dependências do Departamento de Entomologia, Fitopatologia e Zoologia Agrícola da Escola Superior de Agricultura "Luiz de Queiroz" da Universidade de São Paulo (USP/ESALQ), no município de Piracicaba (SP). Foram utilizados tomateiros, Lycopersicon esculentum Mill., da variedade Santa Clara (sementes "Asgrow Vegetable"). O delineamento experimental foi em blocos ao acaso com cinco tratamentos e oito repetições. Cada parcela envolveu oito plantas dispostas em fileira simples, sendo ensacadas cinco pencas por parcela.

O terceiro ensaio foi iniciado em 13 de março de 1999 e foi conduzido em campo comercial de tomates no município de Elias Fausto (SP). Foram utilizados tomateiros híbridos Carmen (sementes "Agroflora"). Foi adotado o delineamento experimental em blocos ao acaso com cinco tratamentos e quatro repetições. Cada parcela envolveu dez plantas dispostas em fileiras duplas, sendo ensacadas cinco pencas por parcela.

Os tomateiros foram plantados e estaqueados em fileira dupla de $90 \times 60 \times 50 \mathrm{~cm}$. Realizaram-se transplante, tutoramento, amarrio, capação, desbrota, amontoa, calagem, adubação com micro e macronutrientes, irrigação e controle químico de pragas, doenças e plantas daninhas.

Para confecção dos saquinhos optou-se pelo papel-manteiga por possuir as seguintes características: resistência ao rompimento e ao molhamento; permeabilidade à trocas gasosas dos frutos; flexibilidade para ser amarrado na penca sem danificá-la; disponibilidade no mercado local e baixo custo. As dimensões do saquinho foram de $35 \times 30 \mathrm{~cm}$. Foram ensacadas as primeiras pencas de tomates, com no mínimo os primeiros dois frutos da penca em início de desenvolvimento, para prevenir posturas. Os saquinhos foram amarrados acima do primeiro fruto da penca, para permitir o desenvolvimento normal dos frutos e evitar acúmulo de água (Figura 1).

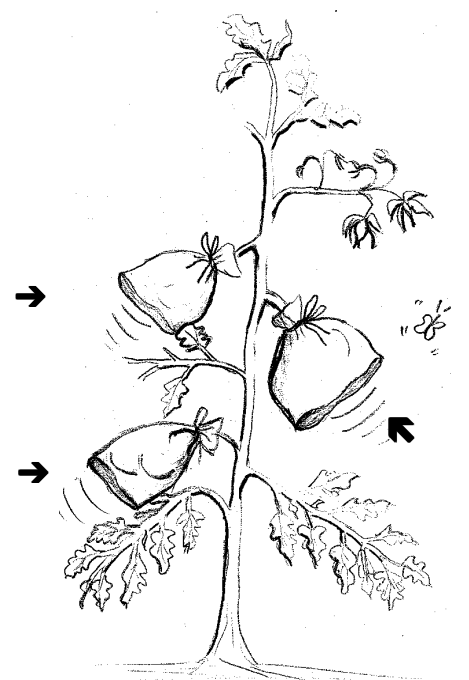

Figura 1 - llustração de um tomateiro, em que as setas indicam a disposição dos saquinhos quando amarrados às pencas e sua região inferior aberta ("sem fundo"). 
Além do efeito do ensacamento testaram-se dois repelentes, pastilha desodorizante e dente de alho, os quais foram colados no interior dos saquinhos, com tamanhos de aproximadamente $90 \mathrm{~mm}^{3}$. A pastilha desodorizante consistiu em um material sólido que é utilizado como fragrância em vasos sanitários (Dodecilbenzeno Sulfonato de Sódio), que em contato com a umidade do ar e a água das irrigações, produz espuma e odores.

Os cinco tratamentos avaliados foram: A: saquinhos contendo pastilha desodorizante; $B$ : saquinhos contendo dente de alho; C: saquinhos vazios; D: testemunha e E: padrão ou controle químico. Nas parcelas da testemunha, os frutos não foram pulverizados com inseticida e nem ensacados. As parcelas padrão, com controle químico de pragas, foram pulverizadas semanalmente com o inseticida sistêmico organofosforado metamidofós ( $60 \mathrm{~g}$ i.a. $100 \mathrm{~L}^{-1}$ ), durante 35 dias, de acordo com recomendação de Andrei (1999).

Os frutos produzidos foram colhidos e avaliados quando estavam próximo ao ponto de maturação. Os resultados foram avaliados de acordo com o número médio de lagartas, por tratamento, encontrado nos frutos produzidos. Os números médios de lagartas de $N$. elegantalis, $H$. zea e $T$. absoluta foram transformados em $\sqrt{(x+1)}$. Os resultados obtidos foram submetidos à análise de variância e comparadas pelo teste de Tukey, a $5 \%$, seguindo metodologia proposta por Gomes (1990).

\section{Análise de resíduos de metamidofós}

$O$ ensaio foi realizado em campo comercial de tomates no município de Elias Fausto (SP), utilizandose tomateiros híbridos Carmen (sementes "Agroflora").

Foram realizados dois tratamentos: pulverização em frutos expostos diretamente ao inseticida e pulverização em frutos protegidos por saquinhos.

Próximo ao ponto de maturação, os frutos foram pulverizados com o inseticida sistêmico organofosforado metamidofós $\left(60 \mathrm{~g}\right.$ i.a. $\left.100 \mathrm{~L}^{-1}\right)$. Logo após a pulverização, colheram-se aleatoriamente, duas amostras de frutos, de aproximadamente $1,0 \mathrm{~kg}$. Tais amostras foram levadas ao Laboratório de Resíduos de Pesticidas do Departamento de Entomologia, Fitopatologia e Zoologia Agrícola da USP/ESALQ, e analisadas de acordo com a metodologia proposta por Andersson \& Pålsheden (1991). Os resultados obtidos foram comparados com a quantidade máxima de resíduos de metamidofós de acordo com Brasil (1995).

\section{Análise físico-química de tomates ensacados em saquinhos de papel-manteiga}

$O$ experimento foi realizado nas dependências do Departamento de Entomologia, Fitopatologia e Zoologia Agrícola da Escola Superior de Agricultura "Luiz de Queiroz" da Universidade de São Paulo (USP/ESALQ), no município de Piracicaba (SP). Foram utilizados tomateiros da variedade Santa Clara (sementes "Asgrow Vegetable").
Foi utilizado o delineamento inteiramente casualizado, com 4 tratamentos e 4 repetições: A: saquinhos contendo pastilha desodorizante; $B$ : saquinhos contendo dente de alho; C: saquinhos vazios e D: testemunha. Nas parcelas da testemunha foi utilizado o método de controle químico de pragas. Próximo ao ponto de maturação, os frutos foram pulverizados com o inseticida sistêmico organofosforado metamidofós $(60 \mathrm{~g}$ i.a. $\left.100 \mathrm{~L}^{-1}\right)$. Aleatoriamente, amostras de aproximadamente $1,0 \mathrm{~kg}$ de frutos foram colhidas em cada tratamento e levadas ao Laboratório de Irradiação de Alimentos e Radioentomologia do Centro de Energia Nuclear na Agricultura (USP/CENA), em Piracicaba (SP).

Foram analisados os seguintes parâmetros físicos e químicos: coloração, firmeza (textura), teor de sólidos solúveis (TSS), acidez titulável (AT), valor "Ratio" e $\mathrm{pH}$.

\section{Parâmetros físicos}

a) Coloração: foram realizadas duas medições em diferentes partes do fruto. $O$ aparelho utilizado foi o colorímetro modelo CR-200 (Minolta, Osaka, Japan). Foram avaliados os elementos $L^{*}$, $a^{*}$ e $b^{*}$, sendo que $a^{*}$ e $b^{*}$ podem ser expressos pelo valor "Chroma". O valor "Chroma" é relativo à coloração dos tomates e é obtido pela fórmula "Chroma" $=\left(a^{* 2}+b^{* 2}\right)^{1 / 2}$, descrita por McGuire (1992), Voss (1992), Tijskens \& Evelo (1994) e Chervin et al. (1996).

b) Firmeza: medida por resistência ao penetrômetro de sensibilidade $2 \mathrm{~N}$ (Newton), modelo FDN 2, marca Wagner Dial Force e pelo Fruit Pressure Tester, modelo FT 327 (3-27 lbs), em dois pontos opostos dos tomates.

\section{Parâmetros químicos}

a) Teor de sólidos solúveis (TSS): foi utilizado o refratômetro Auto Abbe, modelo 10500SN, com temperatura corrigida e valores expressos em Graus Brix.

b) Acidez titulável (AT): determinada por titulometria com solução de $\mathrm{Na}(\mathrm{OH})$, sendo os valores expressos em porcentagem de ácido. Determinou-se os valores de AT para se calcular o valor "Ratio", relação sólidos solúveis/acidez titulável.

c) $\mathrm{pH}$ : foi utilizado o potenciômetro marca Digimed, modelo DMPH-2.

d) Valor "Ratio" (Relação TSS/AT): determinado pelo quociente entre o teor de sólidos solúveis (TSS) e a acidez titulável (AT).

Os resultados foram expressos pelas médias seguidas do erro padrão da média de acordo com Gomes (1990). Devido às suposições de normalidade e homogeneidade de variâncias, requeridas pela estatística paramétrica, não terem sido satisfeitas para os dados originais ou transformados, optou-se pela análise estatística não-paramétrica. Desta forma, os dados foram submetidos ao teste de Kruskal-Wallis, a $5 \%$, por ser o teste não-paramétrico mais adequado para delineamentos inteiramente casualizados (Campos, 1983). 


\section{Viabilidade econômica do método de ensacamento das pencas de tomates}

O ensaio foi realizado em campo comercial de tomate no município de Elias Fausto (SP). Foram utilizados tomateiros híbridos Carmen (sementes "Agroflora"). Para os dois métodos de controle, os tomateiros foram plantados em fileira dupla de $90 \times 60 \times 50 \mathrm{~cm}$. O sistema de cultivo foi de acordo com Cezar et al. (1991) no qual são desenvolvidas diversas atividades como transplante, tutoramento, amarrio, capação, desbrota, amontoa, calagem, adubação com micro e macronutrientes, irrigação e controle químico de pragas, doenças e plantas daninhas. Para o controle químico das pragas, os frutos foram pulverizados semanalmente com 0 inseticida sistêmico organofosforado metamidofós (60 gi.a. $\left.100 \mathrm{~L}^{-1}\right)$.

Os dados utilizados para elaboração dos coeficientes técnicos da cultura do tomateiro foram obtidos nos experimentos conduzidos e na literatura (Informações Econômicas, 1999). O cálculo do custo de produção foi baseado na metodologia proposta por Matsunaga et al. (1976), para um ciclo da cultura, não se considerando meeiros. Os preços dos insumos são referentes à junho de 1999. Os preços de venda dos tomates foram baseados nas médias da CEAGESP, no período de 1994 a 1998, de acordo com Camargo Filho (1999).

\section{RESULTADOS E DISCUSSÃO}

\section{Ensacamento de frutos do tomateiro visando ao controle de pragas}

A Tabela 1 apresenta o número médio de lagartas de $N$. elegantalis e $H$. zea, em cada tratamento, para os frutos colhidos em 22 de julho de 1998, em Piracicaba (SP). Nesta época, não foram encontradas minas nos frutos causadas por $T$. absoluta, possivelmente por haver menor ocorrência desta praga na época estudada, porém a traça-do-tomateiro foi observada alimentando-se preferencialmente do parênquima foliar, sendo encontrada também broqueando os ponteiros. Sua maior infestação, em Piracicaba (SP), ocorre nos meses de janeiro e fevereiro (Paulo, 1986).
A maior ocorrência verificada neste ensaio foi de $N$. elegantalis. Este resultado está de acordo com a literatura, pois há maiores densidades populacionais desta praga nos meses de maio, junho e julho (Coelho, 1977).

Não houve diferença significativa entre os tratamentos saquinhos contendo pastilha desodorizante, saquinhos contendo dente de alho, saquinhos vazios e padrão ou controle químico, somente entre estes e a testemunha, tanto para o controle de $N$. elegantalis como para $H$. zea (Tabela 1 ). O ensacamento dos frutos, associado ou não aos repelentes, além de ter reduzido o ataque das lagartas de $N$. elegantalis e $H$. zea, apresentou resultados semelhantes ao controle químico de pragas. No entanto, o tratamento saquinhos vazios, esteve no limiar de eficiência e não eficiência para $N$. elegantalis, pois se assemelhou também à testemunha. As menores médias foram apresentadas pelo tratamento saquinho com pastilha desodorizante, no controle das duas pragas $(0,0$ para $N$. elegantalis e 0,13 para $H$. zea), estando tais médias abaixo da apresentada pelo controle químico $(0,08$ e 0,30 respectivamente).

A eficiência de todos os tratamentos foi acima de $70,0 \%$ para o controle de $N$. elegantalis. Para $H$. zea, somente o tratamento saquinhos com pastilha desodorizante (A) atingiu este percentual, sendo bastante superior aos demais tratamentos que ficaram em torno de $40,0 \%$, inclusive o controle químico.

A Tabela 2 apresenta o número médio de lagartas de $N$. elegantalis, $H$. zea e $T$. absoluta, em cada tratamento, para a colheita realizada em 21 de dezembro de 1998, em Piracicaba (SP).

Para $N$. elegantalis e $H$. zea não houve diferença significativa entre os tratamentos saquinhos contendo pastilha desodorizante, saquinhos contendo dente de alho, saquinhos vazios e padrão ou controle químico, somente entre estes e a testemunha. Para $T$. absoluta, os tratamentos saquinhos contendo pastilha desodorizante, saquinhos contendo dente de alho e saquinhos vazios apresentaram resultados semelhantes à testemunha. Já entre estes tratamentos e o controle químico, as diferenças foram significativas. O

Tabela 1 - Número médio de lagartas de $N$. elegantalis e $H$. zea, em cada tratamento, para a colheita realizada em 22 de julho de 1998, em Piracicaba (SP).

\begin{tabular}{lcc}
\hline Tratamento & Neoleucinodes elegantalis & Helicoverpa zea \\
\hline & $0,1 \pm 0,01 \mathrm{a}$ & $0,1 \pm 0,04 \mathrm{a}$ \\
Saquinho + pastilha desod orizante & $0,2 \pm 0,04 \mathrm{a}$ & $0,3 \pm 0,05 \mathrm{a}$ \\
Saquinhos + alho & $0,4 \pm 0,04 \mathrm{ab}$ & $0,3 \pm 0,04 \mathrm{a}$ \\
Saquinhos sem repelente & $1,4 \pm 0,18 \mathrm{~b}$ & $0,7 \pm 0,09 \mathrm{~b}$ \\
Testemunha & $0,1 \pm 0,02 \mathrm{a}$ & $0,3 \pm 0,08 \mathrm{a}$ \\
Padrão & 19,2 & 16,0 \\
\hline C.V. $\%$ (\%) & & \\
\hline
\end{tabular}

$\mathrm{n}=8$, EP: Erro padrão da média, C.V.: Coeficiente de variação,

Médias na coluna seguidas da mesma letra não diferem significativamente a $5 \%$ pelo teste Tukey. 
ensacamento dos frutos não foi suficiente para reduzir - ataque desta praga, sendo necessária a pulverização com inseticida para evitar perdas na produção. Nesta época, a eficiência dos tratamentos no controle de $N$. elegantalis foi elevada (acima de $87 \%$ ). Para $H$. zea a maior eficiência foi a do tratamento saquinhos com dente de alho (100\%) e a menor eficiência foi para os saquinhos vazios (38\%). Com relação à $T$. absoluta, a eficiência do controle químico foi de $100 \%$.

A Tabela 3 apresenta o número médio de lagartas de $N$. elegantalis e $T$. absoluta, em cada tratamento, para os frutos colhidos em 15 de abril de 1999. Nesta época não se observou a ocorrência de $H$. zea. As maiores densidades populacionais desta praga são observadas nos meses de setembro, outubro e novembro (Silveira Neto et al., 1973).

Os resultados deste ensaio novamente não demonstraram diferenças no controle de $N$. elegantalis para os tratamentos saquinhos contendo pastilha desodorizante, saquinhos contendo dente de alho, saquinhos vazios e padrão ou controle químico, somente entre estes e a testemunha. A eficiência de todos os tratamentos foi elevada (próxima a 100\%). Para $T$. absoluta, não houve diferença significativa entre todos os tratamentos. Este resultado pode estar relacionado à baixa incidência desta praga na época avaliada, pois foram encontradas apenas 0,13 lagarta em média, para a testemunha. Sendo assim, para $T$. absoluta este ensaio não apresentou resultados satisfatórios para que os tratamentos fossem avaliados.

No tratamento saquinhos com alho, o repelente se deteriorou em pouco tempo, não estando ativo durante todo o período de formação dos frutos, que é de aproximadamente 35 a 40 dias. A razão da deterioração dos dentes de alho foi devido à exposição ao ambiente quando colados nos saquinhos de papel, pois ficaram sujeitos às ações de fungos saprófitas e ao ressecamento que impediram a liberação dos compostos voláteis de repelência antes do término de formação dos tomates.

\section{Análise de resíduos de metamidofós}

A amostra dos frutos que ficaram expostos diretamente ao inseticida apresentou $1,8 \mathrm{mg} \mathrm{kg}^{-1} \mathrm{de}$ resíduos de metamidofós. A amostra composta pelos frutos ensacados apresentou $0,1 \mathrm{mg} \mathrm{kg}^{-1}$, valor 18 vezes inferior ao da amostra anterior. De acordo com Brasil (1995), a quantidade máxima de resíduo de metamidofós permitida é $0,3 \mathrm{mg} \mathrm{kg}^{-1}$. Para atingir este valor, prevê-se um período de carência de 21 dias, durante o qual os frutos são mantidos na planta enquanto o inseticida vai se degradando. No entanto, o florescimento e a frutificação do tomateiro ocorrem primeiro na região inferior e posteriormente no ápice. O amadurecimento dos frutos tem o mesmo comportamento. Esta característica tem favorecido o desrespeito ao período de carência dos agrotóxicos

Tabela 2 - Número médio de lagartas de $N$. elegantalis, $H$. zea e $T$. absoluta, em cada tratamento, para a colheita realizada em 21 de dezembro de 1998, em Piracicaba (SP).

\begin{tabular}{lccc}
\hline Tratamento & Neoleucinodes elegantalis & Helicoverpa zea & Tuta absoluta \\
\hline Saquinhos + pastilha desodorizante & $0,1 \pm 0,01 \mathrm{a}$ & $0,1 \pm 0,02 \mathrm{a}$ & $0,4 \pm 0,06 \mathrm{a}$ \\
Saquinhos + alho & $0,1 \pm 0,02 \mathrm{a}$ & $0,1 \pm 0,01 \mathrm{a}$ & $0,2 \pm 0,03 \mathrm{a}$ \\
Saquinhos sem repelente & $0,1 \pm 0,01 \mathrm{a}$ & $0,3 \pm 0,04 \mathrm{a}$ & $0,3 \pm 0,03 \mathrm{a}$ \\
Testemunha & $1,0 \pm 0,15 \mathrm{~b}$ & $0,6 \pm 0,06 \mathrm{~b}$ & $0,6 \pm 0,04 \mathrm{a}$ \\
Padrão & $0,1 \pm 0,02 \mathrm{a}$ & $0,1 \pm 0,01 \mathrm{a}$ & $0,1 \pm 0,01 \mathrm{~b}$ \\
\hline C.V. (\%) & 17,2 & 10,7 & 11,6 \\
\hline
\end{tabular}

$\mathrm{n}=8$, EP: Erro padrão da média, C.V.: Coeficiente de variação,

Médias na coluna seguidas da mesma letra não diferem significativamente a $5 \%$ pelo teste Tukey.

Tabela 3 - Número médio de lagartas de N. elegantalis e T. absoluta, em cada tratamento, para a colheita realizada em 15 de abril de 1999, em Elias Fausto (SP).

\begin{tabular}{lcr}
\hline Tratamento & Neoleucinodes elegantalis & Tuta absoluta \\
\hline Saquinhos + pastilha desodorizante & $0,1 \pm 0,03 \mathrm{a}$ & $0,1 \pm 0,01 \mathrm{a}$ \\
Saquinhos + alho & $0,1 \pm 0,01 \mathrm{a}$ & $0,1 \pm 0,03 \mathrm{a}$ \\
Saquinhos sem repelente & $0,1 \pm 0,03 \mathrm{a}$ & $0,1 \pm 0,01 \mathrm{a}$ \\
Testemunha & $2,0 \pm 0,84 \mathrm{~b}$ & $0,1 \pm 0,12 \mathrm{a}$ \\
Padrão & $0,1 \pm 0,03 \mathrm{a}$ & $0,1 \pm 0,01 \mathrm{a}$ \\
\hline C.V. (\%) & 28,2 & 19,7 \\
\hline
\end{tabular}

$\mathrm{n}=4$, EP: Erro padrão da média, C.V.: Coeficiente de variação,

Médias na coluna seguidas da mesma letra não diferem significativamente a $5 \%$ pelo teste Tukey. 
aplicados na tomaticultura, pois poderá haver perdas, caso se espere os 21 dias.

A quantidade de resíduos de metamidofós nos frutos não ensacados foi seis vezes superior ao máximo permitido, enquanto que os frutos ensacados apresentaram quantidade três vezes inferior a este limite. $O$ saquinho de papel-manteiga impede que grande parte do inseticida atinja o fruto, mantendo a quantidade de resíduos bem abaixo do limite tolerado, mesmo logo após a pulverização. Adotando-se este método, não é necessário cumprir o período de carência recomendado para o inseticida.

\section{Análise físico-química de tomates ensacados em saquinhos de papel-manteiga}

Para todos os parâmetros avaliados (Tabela 4), não houve diferenças significativas entre os tratamentos. O ensacamento das pencas de tomates, estando associado ou não aos repelentes de insetos, não modificou as características físicoquímicas dos tomates. Este fato permite inferir que as características organolépticas e a aparência dos tomates não se alteraram. Isto devido às características do papel e dos repelentes utilizados. O papel branco, permeável e com ligeira transparência foi colocado sem fundo sendo que segundo as análises físico-químicas não afetou consideravelmente os processos de fotossíntese, respiração e transpiração. Quanto aos repelentes, possuem liberação suave de aromas não modificando o cheiro e gosto dos tomates. Para maiores detalhes do sabor destes tomates serão necessárias análises sensoriais.

Dentre os parâmetros analisados, o fato de a coloração dos tomates não se alterar é um fator extremamente importante, pois é um dos mais observados pelo consumidor. $O$ tomate é um fruto climatérico e a sua coloração é uma mudança muito evidente (Wills et al., 1982).

\section{Viabilidade econômica do método de ensacamento das pencas de tomates}

Os coeficientes técnicos e a estimativa do custo operacional para os dois métodos analisados são apresentados nas Tabelas 5 e 6 , respectivamente.
Em janeiro de 1993 o Instituto de Economia Agrícola (IEA) estimou o custo de produção de 1,0 ha de tomates estaqueado, com controle químico de pragas, em US\$9.845,57. Este valor está acima do calculado neste trabalho para o controle químico (US\$ 9.168,25), mas próximo ao método de controle de pragas através do ensacamento (US\$ 10.217,85).

Em comparação ao controle químico de pragas houve aumento de US $\$ 1.049,60 \mathrm{ha}^{-1}(11,45 \%)$ no custo operacional de produção utilizando-se o ensacamento das pencas de tomates (Tabela 6). No item operações manuais, houve aumento de US $\$ 393,60 \mathrm{ha}^{-1}$, que correspondeu ao acréscimo de 49,2 DH necessários para as operações de colocação dos saquinhos nas pencas. Quanto aos materiais de consumo, houve um aumento de US\$ $1.356,00 \mathrm{ha}^{-1}$, que correspondeu à maior aquisição de barbantes, pois além da amarração dos tomateiros nas estacas foi necessário amarrar os saquinhos nas pencas; à aquisição de papel-manteiga para confecção dos saquinhos e à obtenção do selo de certificação, que dará ao consumidor a garantia do produto adquirido. No entanto, houve redução de US\$ 700,00 no item referente aos defensivos (inseticidas, fungicidas, bactericidas, herbicidas etc), pois após o início da frutificação, cerca de 40 dias após o transplante, não se aplicaram inseticidas para o controle de $N$. elegantalis, $H$. zea e $T$. absoluta.

Caso este método seja adotado como prática comum, fabricantes poderão se interessar em fabricar saquinhos mais práticos, com barbantes aderidos e de rápida e fácil colocação nas pencas. Desta forma, os custos com mão-de-obra e também com materiais de consumo poderão ser reduzidos.

Os tomates produzidos, com controle de pragas realizado através do ensacamento, poderão alcançar preços superiores aos tomates produzidos com controle químico, pois é crescente a demanda por produtos mais saudáveis, sem resíduos de agrotóxicos. Para que o consumidor se sinta seguro em consumir estes tomates e esteja disposto a pagar um preço mais alto, é necessário que o produto seja certificado por órgãos oficiais de fiscalização.

O preço médio do tomate pago ao produtor em São Paulo, embalado em caixa K, é cerca US\$ 3,20 caixa $^{-1}$

Tabela 4 - Valores médios ( \pm EP) de L*, "Chroma", firmeza, teor de sólidos solúveis (TSS), "Ratio" (TSS/AT) e pH das amostras de tomate colhidas nos tratamentos utilizados para o controle de lagartas do tomateiro.

\begin{tabular}{|c|c|c|c|c|c|c|}
\hline \multirow{2}{*}{ Tratamento } & \multicolumn{2}{|c|}{ Coloração } & \multirow{2}{*}{$\begin{array}{l}\text { Firmeza } \\
\left(\times 10^{5} \mathrm{~N}\right)\end{array}$} & \multirow{2}{*}{$\begin{array}{c}\text { TSS } \\
\left({ }^{\circ} \text { Brix }\right)\end{array}$} & \multirow{2}{*}{$\begin{array}{c}\text { "Ratio" } \\
\text { (TSS/AT) }\end{array}$} & \multirow{2}{*}{$\mathrm{pH}$} \\
\hline & $\mathrm{L}^{*}$ & "Chroma" & & & & \\
\hline Saquinho + pastilha dsodorizante & $49,3 \pm 0,66$ & $28,6 \pm 1,12$ & $4,8 \pm 1,49$ & $3,9 \pm 0,09$ & $9,9 \pm 0,41$ & $4,2 \pm 0,03$ \\
\hline Saquinho + alho & $47,7 \pm 2,02$ & $28,4 \pm 2,00$ & $5,5 \pm 1,40$ & $3,8 \pm 0,24$ & $11,1 \pm 0,82$ & $4,2 \pm 0,04$ \\
\hline Saquinho sem repelente & $49,2 \pm 0,57$ & $27,0 \pm 0,24$ & $5,9 \pm 0,69$ & $3,7 \pm 0,11$ & $11,7 \pm 0,26$ & $4,2 \pm 0,01$ \\
\hline Testemunha & $45,3 \pm 1,57$ & $28,8 \pm 0,76$ & $5,8 \pm 1,81$ & $4,1 \pm 0,28$ & $11,5 \pm 1,04$ & $4,3 \pm 0,01$ \\
\hline
\end{tabular}

$n=4$; EP: Erro padrão da média; $L^{*}$ : Elemento numérico relativo a coloração, fornecido pelo colorímetro; AT: Acidez titulável; Diferenças entre os tratamentos não significativas, pela análise estatística não-paramétrica, teste de Kruskal-Wallis, a 5\%. 
(Camargo Filho, 1999). O valor pago por caixa $\mathrm{K}$ de tomate será o determinante para que o produtor opte pelo método do ensacamento das pencas de tomates. Em geral, os produtores levam em consideração o resultado alcançado na safra anterior e o preço do momento para decidir sobre como e qual a área a ser cultivada. A oferta de uma tecnologia é o resultado do esforço de pesquisa e desenvolvimento do setor público e privado e a disponibilização da inovação só acontecerá se existir condições econômicas favoráveis, ou seja, há uma avaliação de viabilidade econômica antes que se tome a decisão de aceitar uma certa tecnologia (Griliches, 1957).

O custo operacional de produção é um instrumento que serve para o agricultor tomar decisões de produção em curto prazo, relativas ao ciclo produtivo da cultura (Martin et al., 1994). Adotar uma tecnologia, como o ensacamento de pencas de tomates é decisão do produtor que levará em consideração o mercado a atingir, o aumento dos custos e da receita a adquirir.
A Figura 2 relaciona o acréscimo no preço mínimo de venda dos tomates e a receita obtida, devido este possível aumento diferencial no custo de produção dos tomates. De acordo com o acréscimo no preço de venda dos tomates aumenta-se também o valor mínimo que deve ser pago por caixa $\mathrm{K}$.

$\mathrm{Na}$ cultura do tomateiro nem sempre chega-se à produtividade esperada de 2500 caixas $\mathrm{K} \mathrm{ha}^{-1}\left(55 \mathrm{t} \mathrm{ha}^{-1}\right)$; há também a possibilidade do preço não atingir o valor mínimo esperado pelo produtor, o que pode diminuir a receita obtida.

O método do ensacamento pode ser considerado uma alternativa para o controle de pragas. O ensacamento de pencas do tomateiro é uma metodologia de cultivo restrito a agricultores em pequena escala de produção e que desejam oferecer ao mercado tomates com redução de defensivos, mais saudáveis, que alcancem maiores preços de venda e atinjam um mercado preferencial.

Tabela 5 - Coeficientes técnicos ha-1 da cultura do tomateiro estaqueado, Lycopersicon esculentum, para dois métodos de controle das lepidobrocas*: químico e ensacamento das pencas, junho de 1999.

\begin{tabular}{|c|c|c|c|}
\hline \multirow{2}{*}{ Operação mecanizada } & \multirow{2}{*}{ Unidade } & \multicolumn{2}{|c|}{ Índice do método } \\
\hline & & Convencional & Ensacamento \\
\hline Aração e gradagem & HM & 3,5 & 3,5 \\
\hline Riscação e sulcamento & $\mathrm{HM}$ & 1,4 & 1,4 \\
\hline Aplicação de calcário & HM & 1,2 & 1,2 \\
\hline Adub ação & $\mathrm{HM}$ & 1,2 & 1,2 \\
\hline Transporte $(200 \mathrm{~km}-18 \mathrm{~T})$ & HM & 3,5 & 3,5 \\
\hline Tanque de pulverização & HM & 31,6 & 31,6 \\
\hline Irrigação & $\mathrm{HM}$ & 36,9 & 36,9 \\
\hline Operação manual & Unidade & \multicolumn{2}{|c|}{ Índice } \\
\hline Coveamento e transplante & $\mathrm{DH}$ & 3,1 & 3,1 \\
\hline Estaqueamento & $\mathrm{DH}$ & 3,8 & 3,8 \\
\hline Amarração, desbrota, capação e raleio do fruto & $\mathrm{DH}$ & 21,4 & - \\
\hline Amarração, desbrota, capação, raleio do fruto e Colocação do saquinho & $\mathrm{DH}$ & - & 70,6 \\
\hline Pulverização & $\mathrm{DH}$ & 4,0 & 4,0 \\
\hline Amontoa & $\mathrm{DH}$ & 9,0 & 9,0 \\
\hline Capina manual e química & $\mathrm{DH}$ & 9,0 & 9,0 \\
\hline Adubação de cobertura & $\mathrm{DH}$ & 8,0 & 8,0 \\
\hline Transporte interno de insumos & $\mathrm{DH}$ & 1,0 & 1,0 \\
\hline Colheita, encaixotamento e carregamento & $\mathrm{DH}$ & 100,0 & 100,0 \\
\hline Material de consumo & Unidade & \multicolumn{2}{|c|}{ Índice } \\
\hline Semente e muda & $\mathrm{g}$ & 40,0 & 40,0 \\
\hline Barbante & $\mathrm{kg}$ & 15,0 & 30,0 \\
\hline Mo urão & un & 340,0 & 340,0 \\
\hline Estaca (com reposição anual de $30,0 \%$ ) & Dz & 917,0 & 917,0 \\
\hline Papel-manteiga & $\mathrm{pc}$ & - & 200,0 \\
\hline Repelente & $\mathrm{cx}$ & - & 500,0 \\
\hline Selo de garantia & 1000un & - & 25,0 \\
\hline Equi pamento de Proteção Individual (EPI) & un & 2,0 & 2,0 \\
\hline Calcário & $\mathrm{t}$ & 6,8 & 6,8 \\
\hline Adubo (NPK: 04-14-08) & $\mathrm{t}$ & 5,5 & 5,5 \\
\hline Adubo (Micronutriente) & $\mathrm{L}$ & 41,0 & 41,0 \\
\hline Inseticida, fungicida, bactericida e herbicida & $\mathrm{kg}, \mathrm{L}$ & 190,0 & 140,0 \\
\hline Embalagem (Caixa K, $22 \mathrm{Kg}$ ) & un & 2750,0 & 2750,0 \\
\hline
\end{tabular}

${ }^{*}$ Neoleucinodes elegantalis, Helicoverpa zea e Tuta absoluta.

HM: Horas-máquina; DH: Dias-homem, considerando 8 horas de trabalho diário. 
Tabela 6 - Custo operacional ha ${ }^{-1}$ da cultura do tomateiro estaqueado, Lycopersicon esculentum, para dois métodos de controle das lepidobrocas*: químico convencional e ensacamento das pencas, junho de 1999.

\begin{tabular}{|c|c|c|c|}
\hline \multirow[t]{2}{*}{ Operação mecanizada } & \multirow[t]{2}{*}{ Valor } & \multicolumn{2}{|c|}{ Valor total } \\
\hline & & \multicolumn{2}{|c|}{ Convencional Ensacamento } \\
\hline & \multicolumn{3}{|c|}{ 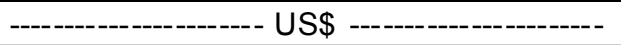 } \\
\hline Aração e gradagem & $0,40 / \mathrm{h}$ & 1,40 & 1,40 \\
\hline Riscação e sulcamento & $0,50 / \mathrm{h}$ & 0,70 & 0,70 \\
\hline Aplicação de calcário & $0,50 / \mathrm{h}$ & 0,60 & 0,60 \\
\hline Adubação & $0,50 / \mathrm{h}$ & 0,60 & 0,60 \\
\hline Transp orte & $11,00 / h$ & 38,50 & 38,50 \\
\hline Tanque de pulverização & $0,50 / \mathrm{h}$ & 15,80 & 15,80 \\
\hline Irrigação & $3,00 / \mathrm{h}$ & 110,70 & 110,70 \\
\hline Sub-total & & 168,30 & 168,30 \\
\hline Operação manual & Valor & \multicolumn{2}{|c|}{ Valor total } \\
\hline Coveamento e transplante & $8,00 /$ dia & 24,80 & 24,80 \\
\hline Estaqueamento & 8,00/dia & 30,40 & 30,40 \\
\hline Amarração, desbrota, capação e raleio do fruto & 8,00/dia & 171,20 & - \\
\hline Amarração, desbrota, capação, raleio dos fruto eColocação do saquinho & 8,00/dia & - & 564,80 \\
\hline Pulverização & $8,00 /$ dia & 32,00 & 32,00 \\
\hline Amontoa & $8,00 /$ dia & 72,00 & 72,00 \\
\hline Capina manual e química & $8,00 /$ dia & 72,00 & 72,00 \\
\hline Adubação de cobertura & 8,00/dia & 64,00 & 64,00 \\
\hline Transporte interno de insumos & $8,00 /$ dia & 8,00 & 8,00 \\
\hline Colheita, encaixotamento e carregamento & 8,00/dia & 800,00 & 800,00 \\
\hline Sub-total & & $1.274,40$ & $1.668,00$ \\
\hline Material de consumo & Valor & \multicolumn{2}{|c|}{ Valor total } \\
\hline Semente e muda & $33,00 / \mathrm{g}$ & $1.320,00$ & $1.320,00$ \\
\hline Barbante & $1,90 / \mathrm{kg}$ & 28,50 & 57,00 \\
\hline Mourão & $1,60 /$ un & 544,00 & 544,00 \\
\hline Papel-manteiga & $5,30 / p c$ & - & $1.060,00$ \\
\hline Repelente & $0,40 / c x$ & - & 200,00 \\
\hline Selo de garantia & $2,70 / 1000$ & - & 67,50 \\
\hline Estaca & $0,50 / \mathrm{Dz}$ & 458,50 & 458,50 \\
\hline Equip. Proteção Individual (EPI) & $16,00 /$ un & 32,00 & 32,00 \\
\hline Calcário & $8,50 / t$ & 57,80 & 57,80 \\
\hline Adubo (NPK: 04-14-08) & $151,50 / \mathrm{t}$ & 833,25 & 833,25 \\
\hline Adubo (Micronutrie nte) & $3,50 / L$ & 141,50 & 141,50 \\
\hline Inseticida, fungicida, bactericida e herbicida & $14,00 / \mathrm{kg}, \mathrm{L}$ & $2.660,00$ & $1.960,00$ \\
\hline Embalagem (Caixa K, 22 Kg) & $0,60 /$ un & $1.650,00$ & $1.650,00$ \\
\hline Sub-total & & $7.725,55$ & $8.381,55$ \\
\hline Total & & $9.168,25$ & $10.217,85$ \\
\hline
\end{tabular}

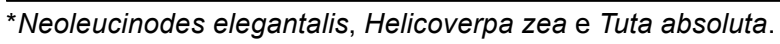

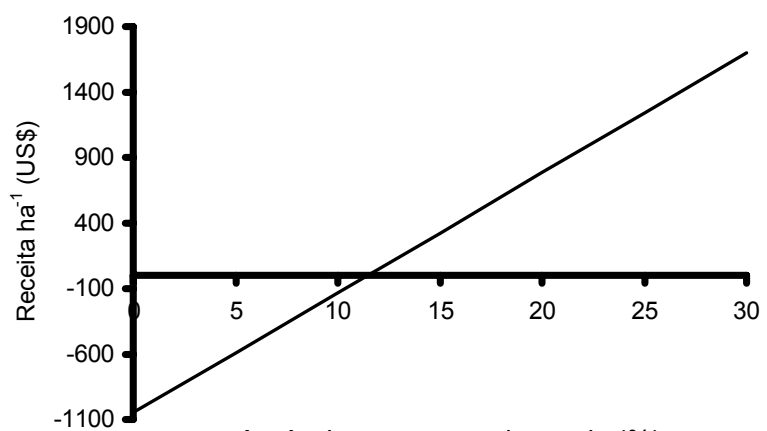

Acréscimo no preço de venda $(\%)$

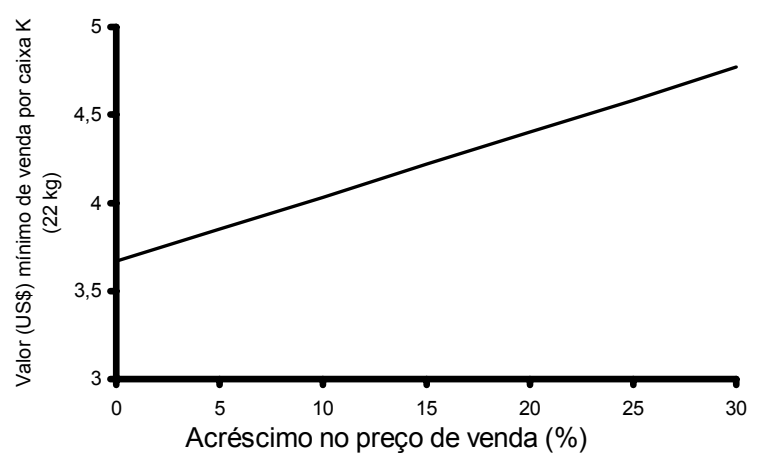

Figura 2 - Receita ha-1 (US\$) relacionada ao aumento de preço na venda de tomates (a) e valor (US\$) mínimo que deve ser pago por caixa $\mathrm{K}$ ao tomate na venda (b) para frutos produzidos com ensacamento das pencas.

Scientia Agricola, v.59, n.2, p.281-289, abr./jun. 2002 


\section{CONCLUSÕES}

O ensacamento dos frutos do tomateiro mostrouse um método de controle de pragas tão eficiente quanto o de controle químico com metamidofós, para Neoleucinodes elegantalis e Helicoverpa zea. Para Tuta absoluta, o ensacamento dos frutos não é suficiente para protegê-los do ataque desta praga, o que se faz com integração em um Manejo Integrado das Pragas.

O ensacamento de pencas do tomateiro é uma prática de cultivo alternativa, restrita a agricultores em pequena escala de produção e que desejam oferecer ao mercado tomates com redução de defensivos, mais saudáveis, que alcancem maiores preços de venda e atinjam um mercado preferencial. Além disso, impede que os frutos tenham contato direto com o inseticida e fungicida normalmente aplicado na cultura. É um método economicamente viável para o controle das pragas dos frutos. Comparado ao controle químico, apresentou $11,45 \%$ de acréscimo no custo operacional de produção.

\section{REFERÊNCIAS BIBLIOGRÁFICAS}

ANDERSSON A.; PÅLSHEDEN, $\mathrm{H}$. Comparison of the efficiency of different GLC multi-residue methods on crops containing pesticide residues. Fresenius' Journal of Analytical Chemistry, v.339, p.365-367, 1991.

ANDREI, E. Compêndio de defensivos agrícolas. 6.ed. São Paulo: Organizações Andrei, 1999. 672p.

BRASIL. Ministério da Saúde. Relação de substâncias para uso fitossanitário e domissanitário: portarias do Ministério da Saúde. São Paulo: International Life Sciences Institute, 1995. p.M-10: Metamidofós.

CAMARGO FILHO, W.P. Mercado brasileiro de tomate. Preços Agrícolas, v.14, p.44, 1999

CAMPOS, H. Estatística experimental não-paramétrica. 4.ed. Piracicaba: FEALQ, 1983. 349p.

CEZAR, S.A.G.; ARRUDA, S.T.; MASCARENHAS, M.D.; MELLO, N.T.C. Sistemas de produção dentro de uma abordagem metodológica de custos agrícolas. Agricultura em São Paulo, v.38, p.117-149, 1991.

CHERVIN, C.; FRANZ, P.; BIRRELL, F. Calibration tile slightly influences assessment of color change in pears from green to yellow using the $L, a$, b space. HortScience, v.31, p.471 1996.

COELHO, I.P. Análise faunística das famílias Pyralidae e Sphingidae (Lepidoptera) através de levantamentos com armadilhas luminosas em Piracicaba. Piracicaba, 1977. 121p. Dissertação (Mestrado) - Escola Superior de Agricultura "Luiz de Queiroz", Universidade de São Paulo.
GOMES, F.P. Curso de estatística experimental. 13.ed. Piracicaba: Nobel, 1990. $468 p$

GOWEN, S.R. Pests. In: GOWEN, S.R. (Ed.) Bananas and plantais. London: Chapman \& Hall, 1995. p.382-402.

GRILICHES, Z. Hybrid corn: an exploration in the economics of technologica change. Econometria, v.25, p.501-522, 1957.

INFORMAÇÕES ECONÔMICAS. São Paulo, v.29, n.6, jun. 1999. 88p.

JANNOYER, M.; CHILLET, M. Improvement of banana growing conditions with the Katryxâ bag. Acta Horticulturae, n.490, p.127-134, 1997.

MACHUCA NETO, M. Aspectos gerais da cultura da macieira no estado de Aomori - Japão. Florianópolis: M. Machuca Neto, 1988. 105p.

MARTIN, N.B.; SERRA, R.; ANTUNES, J.F.G.; OLIVEIRA, M.D.M.; OKAWA, H. Custos: sistema de custo de produção agrícola. Informações Econômicas, v.24, p.98-122, 1994

MATSUNAGA, M.; BEMELMANS, P.F.; TOLEDO, P.E.N.; DULLEY, R.D.; OKAWA, H.; PEDROSO, I.A. Metodologia de custo de produção utilizada pelo IEA. Agricultura em São Paulo, v.23, p.123-139, 1976.

McGUIRE, R.G. Reporting of objective color measurements. HortScience, v.27, p.1254-1255, 1992.

MOREIRA, L.F. Diagnóstico dos problemas ecotoxicológicos causados pelo uso de inseticida (Metamidofós) na região agrícola de Viçosa - MG. Viçosa, 1995. 95p. Dissertação (M.S.) - Universidade Federal de Viçosa.

MOREIRA, L.F.; OLIVEIRA, J.S.; ARAÚJO, J.G.F.; BRAGA, G.M. Homem, meio ambiente e problemas toxicológicos derivados da utilização de inseticidas, na região agrícola de Viçosa-MG. Economia Rural, v.7, p.3438, 1996.

NAKANO, O. Pragas. In: MINAMI, K.; HAAG, H.P. O tomateiro. Campinas: Fundação Cargill, 1989. cap.7, p.235-264.

PAULO, A.D. Época de ocorrência de Scrobipalpula absoluta (Meyrick) (Lepidoptera - Gelechiidae) na cultura do tomate (Lycopersicon esculentum) (Mill.) e seu controle. Piracicaba, 1986. 70p. Dissertação (Mestrado) - Escola Superior de Agricultura "Luiz de Queiroz", Universidade de São Paulo.

RAMOS, M.A.P. Cachos de sol. Globo Rural, v.10, p.63-66, 1994.

RIVADULLA, P.S. Presente y futuro del sector de la uva de mesa embolsada del Vinalopó. Fruticultura Profesional, v.83, p.35-39, 1996.

SCHRECK, C.E. Techniques for the evaluation of insect repellents: a critical review. Annual Review of Entomology, v.22, p.101-119, 1977.

SILVEIRA NETO, S.; FERREIRA, E.; TARRAGO, M.F.S. Estimativa da densidade populacional de Helicoverpa zea (Bod.). Anais da Sociedade Entomológica do Brasil, v.2, p.37-44, 1973

TIJSKENS, L.M.M.; EVELO, R.G. Modelling colour of tomatoes during postharvest storage. Postharvest Biology and Technology, v.4, p.8598, 1994.

VOSS, D.H. Relating colorimeter measurement of plant color to the Royal Horticultural Society Colour Chart. HortScience, v.27, p.1256-1260, 1992.

WILLS, R.B.H.; LEE, T.H.; GRAHAM, D.; McGLASSON, W.B.; HALL, E.G. Postharvest: an introduction to the physiology and handling of fruit and vegetables. 2.ed. Westport: AVI Publishing, 1982. 166p.

$\overline{\text { Recebido em } 05.01 .01}$ 